\title{
Upregulation of the BDNF/TrKB pathway promotes epithelial-mesenchymal transition, as well as the migration and invasion of cervical cancer
}

\author{
YUAN YUAN, HAI-QIONG YE and QIAN-CHUAN REN
}

Department of Gynecology, The Affiliated Hospital of Southwest Medical University, Luzhou, Sichuan 646000, P.R. China

Received August 31, 2017; Accepted December 1, 2017

DOI: $10.3892 /$ ijo.2017.4230

\begin{abstract}
Brain-derived neurotrophic factor (BDNF) has previously been demonstrated to be associated with several types of cancer. In addition, its receptor, tropomyosin related kinase B (TrkB) is involved in tumor invasion and metastasis. Epithelial-mesenchymal transition (EMT) is associated with metastasis in cancers. Thus, The aim of the present study was to examine whether BDNF/TrKB expression is linked to a poor survival and the acquisition of the EMT phenotype in cervical cancer. We found that a high positive expression of BDNF/TrKB was associated with poor survival in cervical cancer. Our results revealed that high expression levels of $\mathrm{BDNF} / \mathrm{TrKB}$ were observed in cervical cancer compared to normal cells. Importantly, we demonstrated that the silencing of TrKB suppressed the activation of EMT via the downregulation of $\mathrm{N}$-cadherin, vimentin, matrix metalloproteinase (MMP)2 and MMP9, and the upregulation of E-cadherin and tissue inhibitor of metalloproteinases (TIMP)2, which resulted in suppressed cell proliferation, migration and invasion. Furthermore, high phosphorylation levels of ERK and Akt were observed in the cervical cancer cells, while these levels were decreased in the cells in which TrKB was knocked down. On the whole, these findings suggest that the BDNF/TrKB pathway is a promising target for the prevention of tumor proliferation, invasion, metastasis and EMT in cervical cancer cells.
\end{abstract}

\section{Introduction}

Cervical cancer is one of the most common gynecological malignancies in clinical practice, and its incidence rate is only followed by breast cancer (1-3). Cervical cancer has a high morbidity and mortality, a poor prognosis and is a serious

Correspondence to: Dr Qian-Chuan Ren, Department of Gynecology, The Affiliated Hospital of Southwest Medical University, 25 Taiping Street, Jiangyang, Luzhou, Sichuan 646000, P.R. China

E-mail: qianchuanren_qcr@163.com

Key words: brain-derived neurotrophic factor, tropomyosin related kinase B, epithelial-mesenchymal transition, extracellular signalregulated kinase, phosphatidylinositol 3-kinase/AKT, cervical cancer threat to women's health $(3,4)$. However, the pathogenesis and etiology of cervical cancer is not yet clear.

Brain-derived growth factor (BDNF) is a high affinity ligand for tropomyosin related kinase B $(\operatorname{TrkB})(5,6)$. The neurotrophin receptor, TrkB, is one of the members of the tropomyosin-related kinase (Trk) family $(5,6)$, and is pivotal to large numbers of biological processes involving the maturity and development of the nervous system, such as neuronal differentiation, growth, invasion and survival $(7,8)$. Previous studies have demonstrated that BDNF/TrkB is involved in growth, invasion and metastasis in several tumors, including gastric cancer, lung cancer, hepatocellular carcinoma, and ovarian and prostate cancer (9-12). The binding of BDNF to TrkB results in TrkB activation, and the two activated TrkBs combine to form homodimers, which phosphorylate several tyrosine residues in the intracellular domain of TrkB. On the one hand, this can enhance the activity of TrkB itself; on the other hand, the phosphorylation of tyrosine residues at certain sites forms a site that specifically binds to PTB and $\mathrm{SH} 2$ structures, attracting cell signaling molecules containing PTB and $\mathrm{SH} 2$ structures, which in turn causes changes in the biological behavior of tumor cells $(5,6,13)$. It has been confirmed that the BDNF/TrkB signal transduction pathway is involved in the regulation of tumor cell proliferation, invasion and metastasis, resistance to chemotherapy and ankylosis by activating the downstream phosphatidylinositol 3-kinase (PI3K)/protein kinase B (PKB, also known as Akt) pathway (14). Epithelial-to-mesenchymal transition (EMT) produces cells with characteristics of stem cells, and is a hallmark of an increased invasive and migratory potential of cancer cells (15-17). During the process of EMT, cells lose cell-cell contacts and intercellular junctions, and undergo cytoskeletal reorganization (17). The increased expression of BDNF/TrkB is closely associated with EMT in several types of tumors, leading to enhanced tumor invasion and metastasis $(18,19)$. These studies suggested that BDNF/TrkB plays an important role in several cancers by enhancing high cell proliferation, invasion and metastasis, the resistance to apoptosis and poor prognosis.

Recent studies have revealed that extracellular signalregulated kinase (ERK) regulates the migration, invasion and proliferation of cervical cancer cells (20-23). These results suggest that the enhanced phosphorylation of ERK promotes cell proliferation, invasion and metastasis $(20-23)$. There is 
evidence to indicate that the activation of the PI3K/AKT pathway contributes to an enhanced invasion and metastasis, and a poor prognosis in cervical cancers $(24,25)$. A recent study revealed that the BDNF/TrkB signaling pathway exerted a marked stimulatory effect on HeLa cells (a cervical cancer cell line) (26). Another study reported that TrkB and BDNF expression may play a significant role in the early events of tumorigenesis in cervical squamous cell carcinoma (SCC) (27). However, the underlying mechanisms of the BDNF/TrkBinduced signaling pathway activation need to be elucidated in cervical cancers. Hence, although BDNF/TrkB is essential in the tumorignicity of many tumors (9-12), it remains obscure as to whether the BDNF/TrkB pathway is associated with metastasis and EMT, and whether it is linked to the ERK or PI3K/ AKT pathways in the development of cervical cancer.

In this study, we investigated the role of the BDNF/TrkB pathway in cervical cancers and cervical cancer cell lines. Our results revealed that high a $\mathrm{BDNF} / \mathrm{TrkB}$ expression was associated with a poor outcome of cervical cancers. Notably, we also found that a high BDNF/TrkB expression was necessary for cell proliferation, invasion, metastasis and EMT, processes regulated by the ERK and PI3K/AKT signaling pathways.

\section{Materials and methods}

Patients. This study was approved by our hospital institutional review board and informed consent was obtained from all patients. In total, 56 patients with cervical cancer (CC) were enrolled in this study, aged between 36 to 71 years, with an average age of 54.6 years. All patients underwent total hysterectomy or radical mastectomy without pre-operative radiotherapy and chemotherapy. Paraffin-embedded specimens from surgical resection, as well as adjacent normal tissues were collected from The Affiliated Hospital of Southwest Medical University, Luzhou between January and October, 2016. CC staging was performed according to the standard of the International Union of Obstetrics and Gynecology (FIGO) in 1998 (28): 45 cases were characterized as having disease at the $>$ IIB stage and 11 cases were characterized as having disease at the $\leq$ IIB. The histological grade of the samples was as follows: 7 cases of poorly differentiated, 24 cases of moderately differentiated and 25 cases of well differentiated tumors. Lymph node metastasis was as follows: 15 cases with lymph node metastases and 41 cases with no lymph node metastases.

Cell culture. The human cervical cancer cell lines, HeLa, SiHa, CaSki, C4-1 and C-33 A, and the human papillomavirus immortalized ectocervical (Ect1/E6E7) cells were purchased from the American Type Culture Collection (ATCC; Manassas, VA, USA), and grown in RPMI-1640 medium containing $10 \%$ fetal bovine serum (FBS) and antibiotics at $37^{\circ} \mathrm{C}$ under a humidified atmosphere with $5 \% \mathrm{CO}_{2}$ and $95 \%$ air.

Cell viability assay. Cell viability was determined using the 3-(4,5-dimethylthiazol-2-yl)-2,5-diphenytetrazolium bromide (MTT) assay kit (Beyotime Institute of Biotechnology, Haimen, China). Briefly, the cells were seeded in 96-well plates and were pre-treated with siRNA against TrKB (siTrKB) or negative siRNA for $24 \mathrm{~h}$. Subsequently, a concentration of $0.5 \mathrm{mg} / \mathrm{ml}$ of $1 \mathrm{mg} / \mathrm{ml} \mathrm{MTT/well} \mathrm{was} \mathrm{added} \mathrm{to} \mathrm{the} \mathrm{cells}$ followed by incubation for $4 \mathrm{~h}$ at $37^{\circ} \mathrm{C}$. The optical density at $490 \mathrm{~nm}$ was measured using a Bio-Rad microplate reader (Bio-Rad, Hercules, CA, USA). Cell viability was calculated as percentage of the average OD value of the control.

Transwell invasion assay and scratch migration assay. The invasion assay of the cells was performed using 24-well Transwell plates (Corning Inc., Lowell, MA, USA). Briefly, $1 \times 10^{5}$ cells in $500 \mu 1$ of Dulbecco's modified Eagle's medium (DMEM) were seeded in the upper chamber. The lower chamber was supplemented with $750 \mu 1$ of DMEM containing $10 \%$ FBS. Follwowing $24 \mathrm{~h}$ of incubation, the upper cells of the membrane were removed using a cotton-tipped swab. The cells invading the underside of the membrane were fixed in methanol for $15 \mathrm{~min}$ and stained with $0.5 \%$ crystal violet (AppliChem GmbH, Darmstadt, Germany) for $15 \mathrm{~min}$. The cell numbers from 5 random fields were calculated and the corresponding images for the selected fields were captured at x40 magnification. The assays were performed in triplicate.

For the scratch assay, the cells were grown in complete DMEM until 90-100\% confluency in cell culture plates. A wound ( $5 \mathrm{~mm}$ in diameter) was introduced across each plate. Wound healing growth or the migration of the cells was observed under a microscope (Olympus CX23; Olympus, Tokyo, Japan) after $24 \mathrm{~h}$.

Animal experiments. BALB/c nude mice (age, 6-8 weeks; sex, male and female; weight, 20-25g) were purchased from the Medical Laboratory Animal Center of Guangdong Province (Guangzhou, China) and were allowed to acclimatize for 2 weeks. Animal experiments in this study were carried out after obtaining ethics approval from the Ethics Committee of the Affiliated Hospital of Southwest Medical University. The mice were maintained in compliance with the Institutional Animal Care and Use Committee (IACUC) procedures and guidelines. The mice had free access to food and water and were kept at a temperature of $20-25^{\circ} \mathrm{C}$, and a relative humidity of $60 \%$. The mice were divided into 3 groups as follows: The control, in which mice were injected with Hela cells; the siNC group, in which mice were injected with HeLa cells transfected with negative control siRNA; and the siTrKB group, in which mice were injected with HeLa cells transfected with siTrKB; there were 5 mice per group. HeLa cells $\left(1 \times 10^{5}\right)$ from all groups were resuspended in $50 \mu \mathrm{l}$ phosphate-buffered saline (PBS) before being injected subcutaneously into the right flanks. Tumors in mice were allowed to grow for 15 days and the mice were then sacrificed and tumors removed.

Silencing of TrKB bysiRNA.Recombinantadenoviruses encoding siRNA targeting TrkB and negative TrkB siRNA were designed and constructed by Sangon Biotech Co., Ltd. (Shanghai, China). The HeLa and CaSki cells at $2 \times 10^{5}$ were seeded in 12 -well plates for $12 \mathrm{~h}$ prior to transfection. After the cells were grown to $70 \%$ confluence, they were divided into 3 groups and they were transfected with $30 \mathrm{nM}$ PBS (control group), viruses encoding TrkB siRNA and negative TrkB siRNA. Following transfection for $48 \mathrm{~h}$, the cells were collected and used in the experiments.

Immunohistochemical (IHC) staining. The tissue samples were fixed in $10 \%$ formalin. All samples were then routinely 
Table I. Association of TrKB and BDNF expression with the clinicopathological characteristics of the patients with cervical cancer.

\begin{tabular}{|c|c|c|c|c|c|}
\hline \multirow[b]{2}{*}{ Characteristics } & \multirow[b]{2}{*}{ No. } & \multicolumn{2}{|c|}{ TrKB } & \multicolumn{2}{|c|}{ BDNF } \\
\hline & & Positive n (\%) & P-value & Positive n (\%) & $\mathrm{P}$-value \\
\hline Age (years) & & & & & 0.810 \\
\hline$<50$ & 39 & $24(61.5)$ & 0.848 & $22(56.4)$ & \\
\hline$\geq 50$ & 17 & $10(58.8)$ & & $9(52.9)$ & \\
\hline Tumor size (cm) & & & & & 0.004 \\
\hline$<4$ & 41 & $22(53.6)$ & 0.112 & $18(43.9)$ & \\
\hline$>4$ & 15 & $12(80)$ & & $13(86.7)$ & \\
\hline Grade of differentiation & & & & & 0.082 \\
\hline Well & 24 & $11(45.8)$ & 0.061 & $10(41.7)$ & \\
\hline Moderate & 25 & $18(72)$ & & $15(60)$ & \\
\hline Poor & 7 & $5(71.4)$ & & $6(85.7)$ & \\
\hline FIGO stage & & & & & 0.312 \\
\hline$<\mathrm{IIB}$ & 45 & $25(55.6)$ & 0.171 & $23(51.1)$ & \\
\hline$\geq \mathrm{IIB}$ & 11 & $9(81.8)$ & & $8(72.7)$ & \\
\hline Histological subtype & & & & & 0.123 \\
\hline Squamous cell carcinoma & 44 & $26(59.1)$ & 0.746 & $22(50)$ & \\
\hline Adenocarcinoma & 12 & $8(66.7)$ & & $9(75)$ & \\
\hline Lymph node & & & & & 0.102 \\
\hline Positive & 15 & $12(80)$ & 0.074 & $11(73.3)$ & \\
\hline Negative & 41 & $22(53.7)$ & & $20(48.8)$ & \\
\hline
\end{tabular}

processed, paraffin embedded, sectioned at $5 \mathrm{~mm}$, and then stained with hematoxylin and eosin (H\&E). The sections were deparaffinized in xylene and rehydrated in a graded series of alcohol solutions according to routine protocol. Subsequently, the sections were incubated with the appropriate primary $\operatorname{TrKB}$ antibodies (1:100 dilution; Abcam, Cambridge, MA, USA) and BDNF antibodies (1:100 dilution; Abcam) overnight. After washing, the slides were incubated for $30 \mathrm{~min}$ at room temperature with goat anti-rat IgG H\&L (HRP). Non-specific staining was blocked with $0.5 \%$ casein and $5 \%$ normal serum (Invitrogen/ Life Technologies, Carlsbad, CA, USA). The sections were subsequently counterstained with hematoxylin (Invitrogen/ Life Technologies). The percentage of positive cells was determined by counting at least 200 cells per section in 5 random, non-overlapping fields under a microscope. Immunostaining was evaluated using a semi-quantitative scoring system, which was determined by the staining intensity in conjunction with the percentage of positively stained cells. Scores of $0,1+$ and $2+$ were regarded as weak or moderate for the expression of TrKB and BDNF protein, whereas scores of 3+ were considered as positive for the overexpression of TrKB and BDNF protein.

Western blot analysis. Cells from all the groups were washed using ice-cold PBS and lysed for $30 \mathrm{~min}$ on ice in lysis buffer (100 mM Tris, $150 \mathrm{mM} \mathrm{NaCl,} \mathrm{1 \%} \mathrm{Triton} \mathrm{X-100)} \mathrm{supplemented}$ with a cocktail of protease inhibitors (Sigma-Aldrich, St. Louis, MO, USA). Protein concentrations were examined using the BCA protein assay kit (Pierce Biotechnology, Rockford, IL, USA) according to the manufacturer's instructions. Briefly, proteins in the cells were separated by an SDS polyacrylamide gel (Pharmacia and Biotech, Piscataway, NJ, USA) electrophoresis, and then electrotransferred onto polyvinylidene difluoride membranes (Millipore Corp., Bedford, MA, USA). The blots were then washed with TBST. The membranes were then blocked with $5 \%$ non-fat dry milk. Subsequently, the membranes were incubated with appropriate antibodies (TrKB, 1:1,000, ab18987; BDNF, 1:1,000, ab108319; E-Cadherin, 1:100, ab1416; N-cadherin, 1:1,000, ab18203; Vimentin, 1:2,000, ab92547; MMP2, 1:1,000, ab37150; MMP9, 1:1,000, ab38898; TIMP2, 1:1,000, ab1828; and GAPDH, 1:1,000, ab8245; all from Abcam) at $4^{\circ} \mathrm{C}$ overnight. The membranes were washed with PBS and incubated with a 1:2,000 dilution of peroxidaseconjugated secondary antibodies (A9044; Sigma-Aldrich) for $1 \mathrm{~h}$. The bands were visualized using the enhanced chemiluminescence (ECL) western blotting detection system (Amersham Bioscience, Piscataway, NJ, USA). The intensity of the bands was determined using ImageJ software (NIH, Bethesda, MD, USA).

$R T$ - $q P C R$ analysis. Total RNA was isolated from the cells in all groups using the RNeasy Mini kit (Qiagen, Valencia, CA, USA) according to the manufacturer's instructions. A total of $1 \mu \mathrm{g}$ total RNA was converted into cDNA using the TaqMan Reverse Transcription reagent kit (Applied Biosystems, Foster City, CA, USA). Quantitative PCR was performed using TaqMan Gene Expression Assays and the TaqMan Universal PCR Master Mix (Applied Biosystems) according to the manufacturer's instructions. The amplification and detection of mRNA 

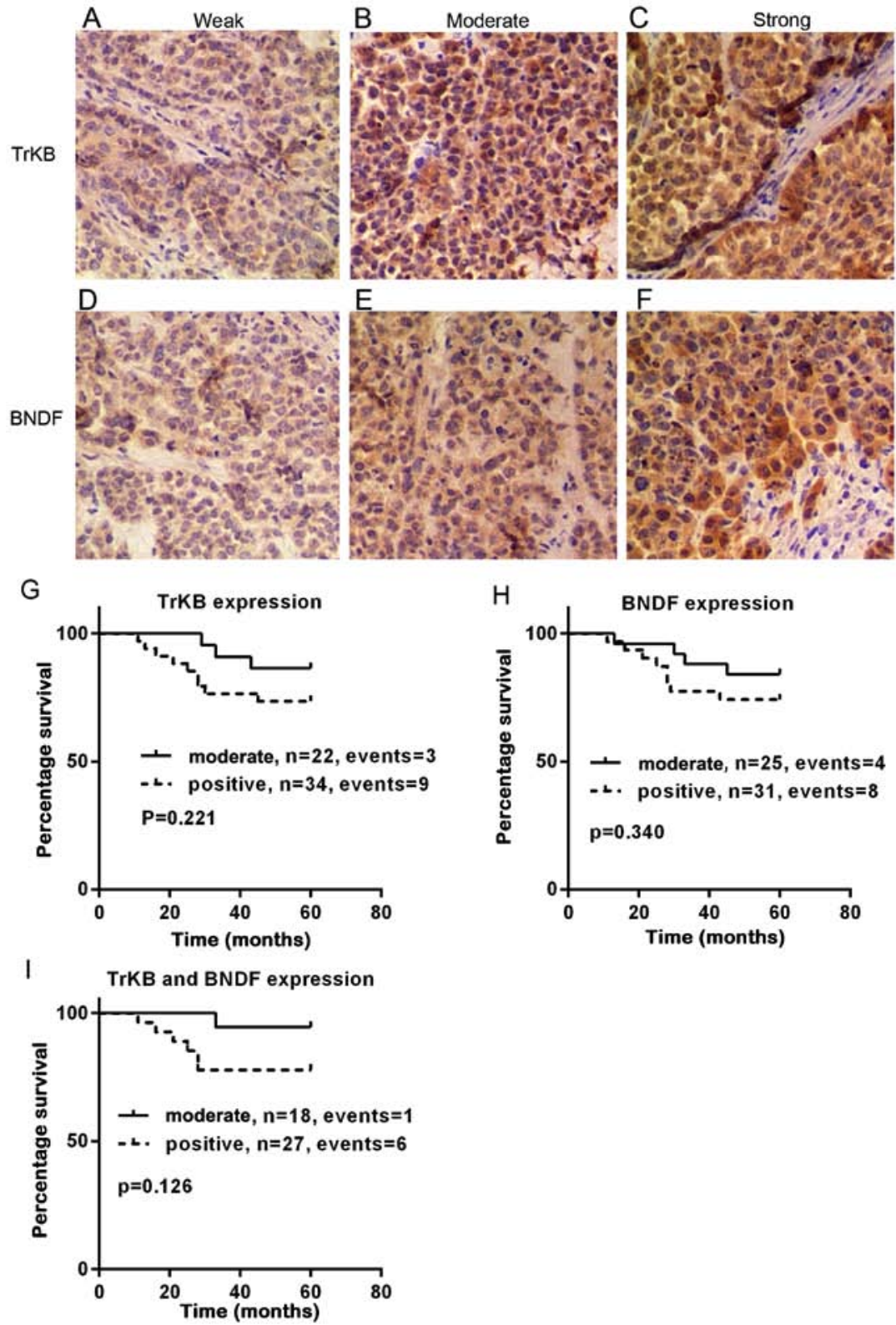

Figure 1. Expression of TrKB or BDNF in patients with cervical cancer and their association with overall survival. Immunohistochemical images for weak, moderate and strong (A-C) TrKB expression and (D-F) BDNF expression. (G) An improved survival time was observed in patients with a moderate expression of TrKB. (H) An improvded survival rate was found in patients with a moderate expression of BNDF. (I) A moderate expression of both TrKB and BDNF was associated with an improved overall survival time.

were analyzed using a 7500 Real-Time PCR System (Applied Biosystems). Data were calculated using the $2^{-\Delta \Delta C q}$ method and normalized to GAPDH levels. The PCR reactions for each sample were performed in duplicate. The sequences primers were used as follows: TrkB forward, 5'-TTGCAGCATTT CACTTGGCT-3' and reverse, 5'-CTG TCATTTAGCCGCG AACA-3'; BDNF forward, 2, 5'-GAGC CCTGTATCAACCC AGA-3' and reverse, 5'-TCAAATACCATGCCCCACCT-3'; E-Cadherin forward, 5'-AACAGGATGGCTGAAGGTGA-3' and reverse, 5'-CCTTCCATGACAGACCCCTT-3'; N-cadherin forward, 5'-ATATTTCCATCCTGCGCGTG-3' and reverse, 5'-GTTTGGCCTGGCGTTCTTTA-3'; vimentin forward, 5'-GAGTCCACTGAGTACCGGAG-3' and reverse, 5'-ACGA GCCATTTCCTCCTTCA-3'; matrix metalloproteinase (MMP)2 forward, 5'-GGAGTACTGCAAGTTCCCCT-3' and reverse, 5'-TCAGTGGTGCAGCTGTCATA-3'; MMP9 forward, 5'-TGCCACTTCCCCTTCATCTT-3' and reverse, 5'-CGTCCT GGGTGTAGAGTCTC-3'; tissue inhibitor of metalloproteinases (TIMP)2 forward, 5'-TGATCCCGTGCTACATC TCC-3' and reverse, 5'-CCTGCTTATGGGTCCTCGAT-3'; and GAPDH forward, 5'-GAGTAAGACCCCTGGACCAC-3' and reverse, 5'-AACTGGTTGAGCACAGGGTA-3'.

Statistical analysis. The data are expressed as the means \pm standard deviation. An independent t-test and one-way ANOVA was used for the statistical comparison of two and multiple groups, respectively followed by Tukey's post hoc test. A value of $\mathrm{P}<0.05$ was considered to indicate a statistically significant difference. All statistical analysis were analyzed using SPSS software (SPSS version 18; SPSS, Inc., Chicago, IL, USA). 

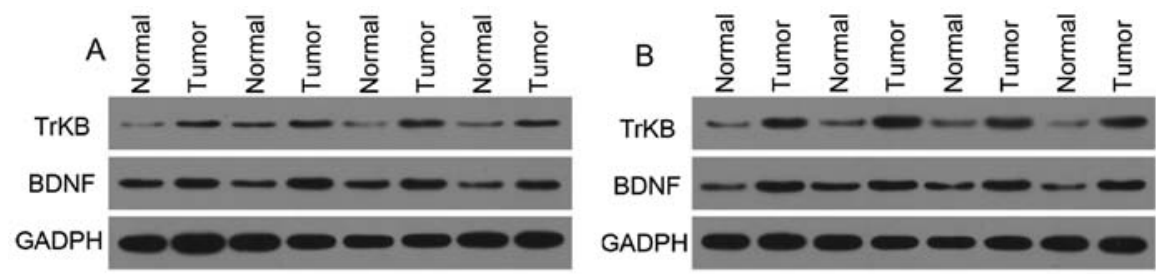

C
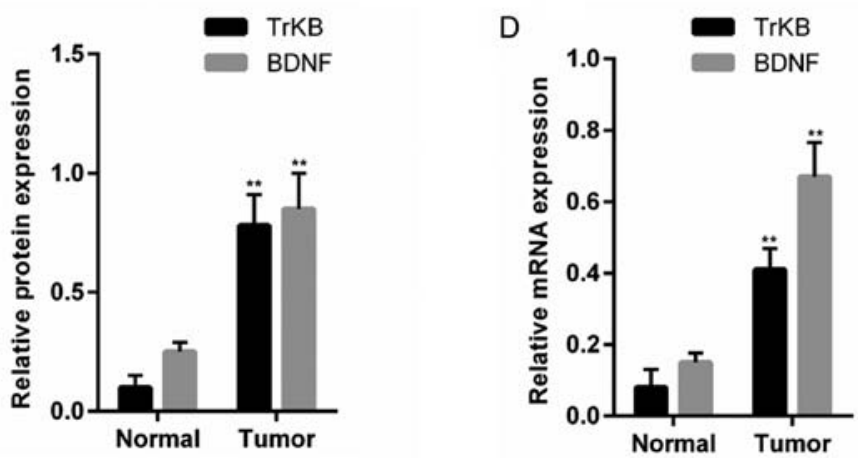

$\mathrm{E}$
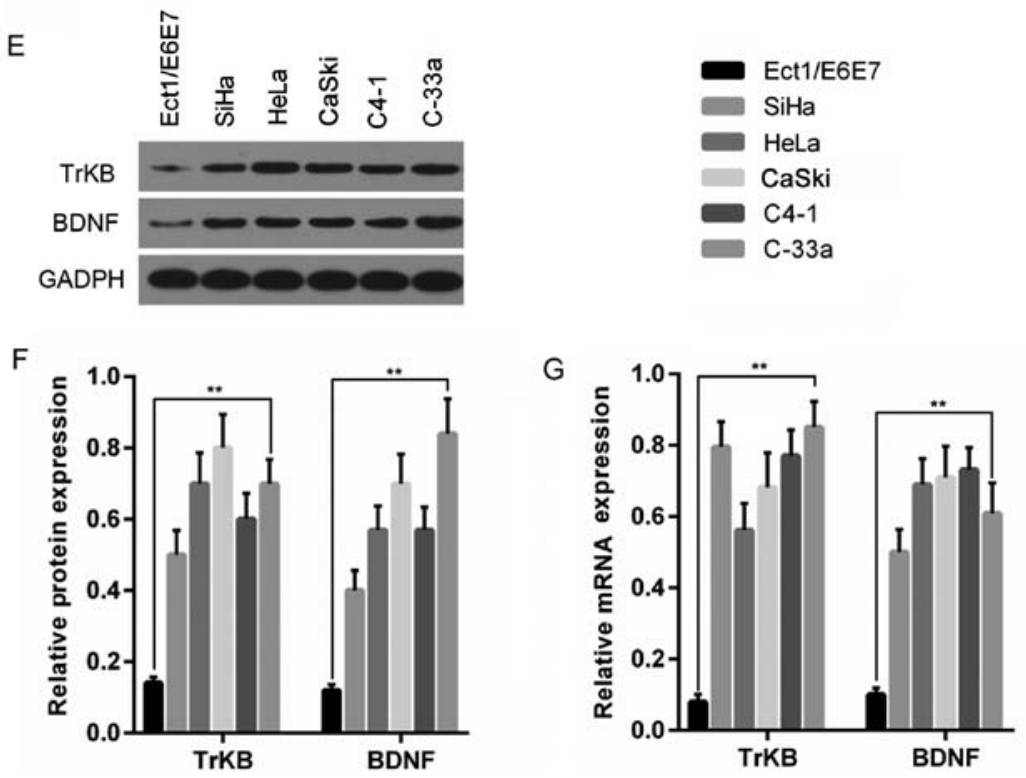

Figure 2. A higher expression of TrKB and BDNF in cervical cancer tissues and cell lines was observed compared to adjacent tissues and human papillomavirus immortalized ectocervical cells (Ect1/E6E7). (A-C) The protein expression levels of TrKB and BDNF were significant higher in tumor tissues compared with those in adjacent normal tissues. (D) RT-qPCR assay revealed a markedly higher mRNA expression of TrKB and BDNF in tumor tissues than in normal tissues. (E and F) The protein expression levels of TrKB and BDNF in the cervical cell lines, HeLa, CaSki, CaSki, C4-1 and C-33 A were clearly higher than those in human papillomavirus immortalized ectocervical cells (Ect1/E6E7). (G) RT-qPCR assay revealed the markedly increased mRNA expression of TrKB and BDNF in HeLa, CaSki, CaSki, C4-1 and C-33 A cells compared to the Ect1/E6E7 cells. ${ }^{* *} \mathrm{P}<0.01$, tumor vs. normal, or cancer cell lines vs. Ect1/E6E7 cells.

\section{Results}

Correlations between $\operatorname{Tr} K B$ and BDNF expression with clinicopathological parameters. The representative immunohistochemical images for TrKB and BDNF are shown in Fig. 1A-F. The association between the clinicopathological parameters and TrKB or BDNF expression are summarized in Table I. Of the 56 patients with cervical cancer, the age of 39 patients was $<50$ years. In total, 45 cases were characterized as having disease at the $>$ IIB stage and 11 cases were characterized as having the disease at the $\leq$ IIB stage. In addition, 44 patients had squamous cell carcinoma and 12 had adenocarcinoma. No significant association between $\operatorname{TrKB}$ expression and clinicopathological parameters was observed.
However, higher expression levels were observed in patients with a tumor size of $>4 \mathrm{~cm}$ compared to those with a tumor sie of $<4 \mathrm{~cm}(\mathrm{P}=0.112)$. Patients with poor and moderate differentiation had a higher $\operatorname{TrKB}$ expression compared to those with well differentiation $(\mathrm{P}=0.061)$. A positive $\operatorname{TrKB}$ expression was found in $81.8 \%(n=9)$ of patients with the disease at $\geq$ IIB stage, while it was $55.6 \%$ in patients with the disease at $<$ IIB stage. The distribution of TrKB protein was markedly higher in patients with lymph node metastasis than in patients with no lymph node metastasis $(\mathrm{P}=0.074)$. Similar to TrKB expression, a high expression of BDNF was found in patients with moderate and poor differentiation, with the disease at $\geq$ IIB stage and with lymph node metastasis. In addition, there was a significant association between BDNF expression and tumor size. The positive 
A
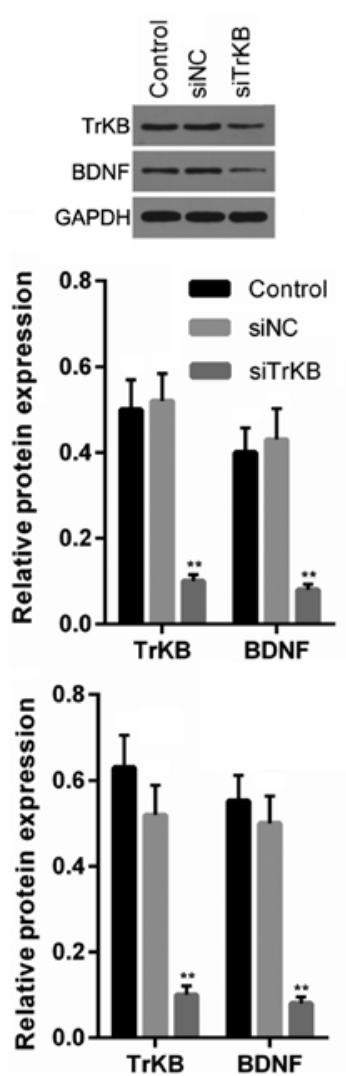

B
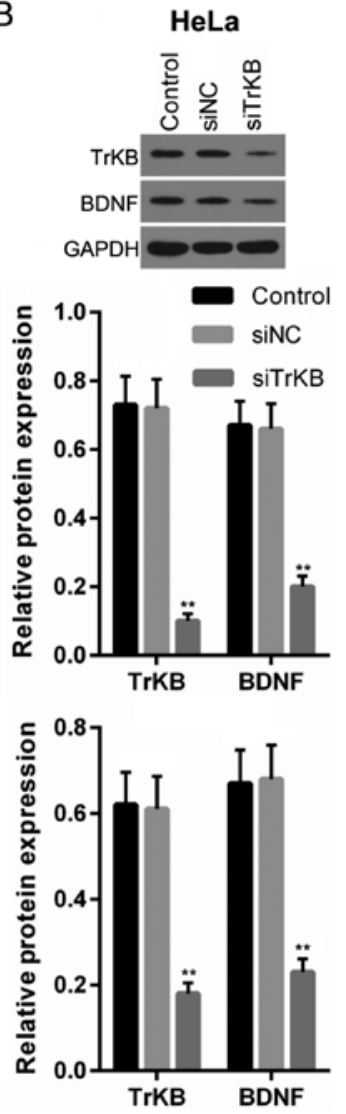

Figure 3. TrKB and BDNF expression levels were significantly decreased in SiHa and HeLa cells after the silencing of TrKB by siRNA (siTrKB). (A) Expression levels of TrKB and BDNF in HeLa cells were markedly decreased following transfection with siTrKB in transcriptional and translational levels. (B) Expression levels of TrKB and BDNF in CaSki cells were markedly decreased following transfection with siTrKB at the transcriptional and translational levels. ${ }^{*} \mathrm{P}<0.05$ vs. control; ${ }^{* *} \mathrm{P}<0.01$ vs. control.

expression of BDNF was $86.7 \%$ in patients with a tumor size of $>4 \mathrm{~cm}(\mathrm{n}=13 / 15)$, significantly higher than tht of patients with a tumor size of $<4 \mathrm{~cm}(43.9 \%$; $=18 / 41)(\mathrm{P}=0.004)$.

Associations between TrKB and BDNF expression with patient overall survival. To evaluate the association between $\operatorname{TrKB}$ or BDNF and the overall survival of patients with cervical cancer, Kaplan-Meier analysis was performed. As shown in Fig. 1G-I, the overall survival time was prolonged in patients with a moderate expression of TrKB and BDNF, compared to that in patients with a positive expression of $\operatorname{TrKB}(\mathrm{P}=0.221)$ and BDNF $(\mathrm{P}=0.340)$, respectively. Furthermore, we compared patients with both TrKB and BDNF positive expression to patients with both TrKB and BDNF moderate expression. It was evident that patients with both TrKB and BDNF moderate expression had a prolonged survival time compared to patients with $\operatorname{TrKB}$ and BDNF positive expression $(\mathrm{n}=45, \mathrm{P}=0.126)$.

Higher expression levels of TrKB or BDNF are observed in cervical cancer tissues than in adjacent normal tissues. To assess the differences in TrKB and BDNF expression between cancer tissues and adjacent normal tissues, we determined the mRNA and the protein expression levels of TrKB and BDNF in these tissues. In 8 paired cancer tissues and adjacent normal

tissues, the expression at both the protein (Fig. 2A-C) and mRNA (Fig. 2D) level were found to be overexpressed in cancer tissues compared to those in the adjacent tissues counterparts.

Expression levels of TrKB and BDNF in cervical cancer cell lines are higher than those in the human papillomavirus immortalized ectocervical cells (Ect1/E6E7). To further explore the role of $\operatorname{TrKB}$ and BDNF in cervical cancer, we examined the expression of TrKB and BDNF in cervical cancer cell lines and human papillomavirus immortalized ectocervical cells (Ect1/E6E7). As shown in Fig. 2E-G, compared to the Ect1/E6E7 cells, higher protein and mRNA expression levels of TrKB and BDNF were observed in the cervical cancer cell lines HeLa, CaSki, CaSki, C4-1 and C-33 A.

Expression levels of $\operatorname{Tr} K B$ and BDNF are significantly decreased in cells following siRNA transfection. To explore the role of TrKB and BDNF in the cervical cancer cell lines, HeLa and CaSki, we silenced TrKB with TrKB siRNA. The results revealed that the protein and mRNA expression levels of both TrKB and BDNF were clearly downregulated after the cells were transfected with TrKB siRNA, compared to the levels in the control and negative siRNA-transfected cells (Fig. 3).

The proliferative, migrative and invasive ability of the cervical cancer cell lines, HeLa and CaSki, were significantly suppressed after the cells were transfected with TrKB siRNA. MTT assay revealed that cell growth was inhibited after the cells were transfected with TrKB siRNA compared to control and negative siRNA-transfected cells. For the HeLa cells, the cell viability at day 3 was $\sim 3$-fold of that at day 0 in both the control and negative siRNA-transfected groups, while in the TrKB siRNA-transfected group, it was only elevated $\sim 0.7$ fold at day 3 compared to day 0 (Fig. 4A). Similarly, for the CaSki cells, the cell viability was enhanced $\sim 1.5$-fold at day 3 compared to that at day 0 in both the control and negative siRNA-transfected groups, whereas it was only increased $\sim 0.5$ fold at day 3 compared to day 0 (Fig. 4B).

Transwell invasion assay revealed that the invasive ability was markedly suppressed in the cells in which TrKB was knocked down compared with the control and negative siRNAtransfected group. The numbers of invaded cells were $~ 100$ for both the HeLa and CaSki cells from the control and negative siRNA-transfected group, whereas the numbers were $\sim 25$ and 10 for the HeLa and CaSki cells from TrKB siRNA-transfected group, respectively (Fig. 4C and D).

The scratch wound healing assay was performed to examine the effects of the knockdown of TrKB on the proliferative and migratory abilities of the cells. It was clearly revealed that the wound healing ability of the cells from the control and negative siRNA-transfected groups was significantly higher than that in the cells transfected with TrKB siRNA. The wound areas were filled $\sim 90 \%$ in both the HeLa and CaSki cells from the control and negative siRNA-transfected groups, while they were $\sim 50$ and $35 \%$ in the HeLa and CaSki from the TrKB siRNA-transfected group, respectively (Fig. 5).

Silencing of $\operatorname{Tr} K B$ expression inhibits the expression of cell EMT-related proteins. EMT plays an important role in the invasion and metastasis of tumor cells. We determined the effects of the knockdown of TrKB on the expression of 

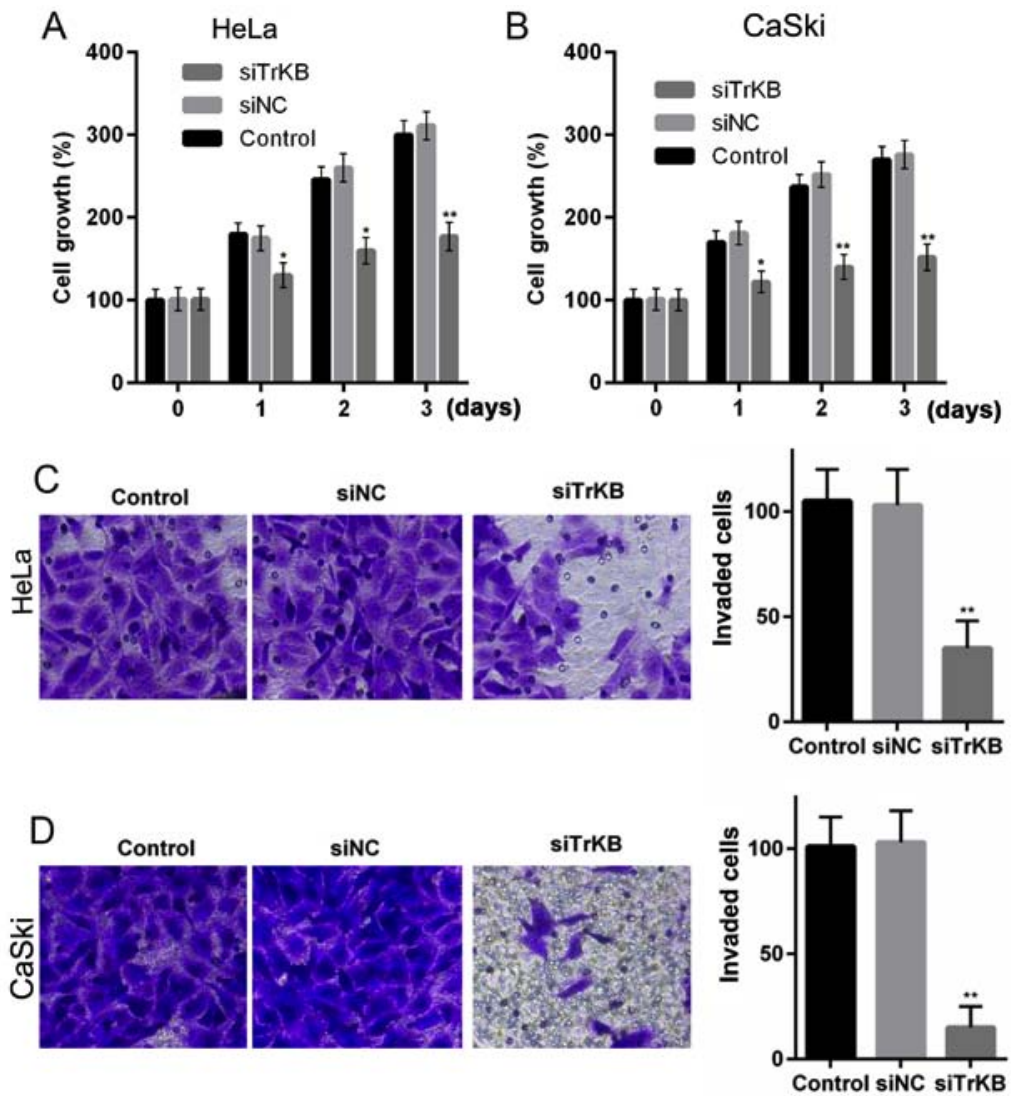

Figure 4. The proliferative and invasive ability of the cervical cancer cell lines were significantly inhibited in cells transfected with TrKB siRNA. MTT assay revealed that cell growth rate of both the (A) HeLa and (B) CaSki cells transfected with siTrKB was markedly reduced compared to the control and negative control groups (siNC). Transwell invasion assay revealed that the invasion rate was markedly lower in both the (C) HeLa and (D) CaSki cells transfected with siTrKB compared with the control and negative control group. ${ }^{*} \mathrm{P}<0.05$ vs. control; ${ }^{* *} \mathrm{P}<0.01$ vs. control.
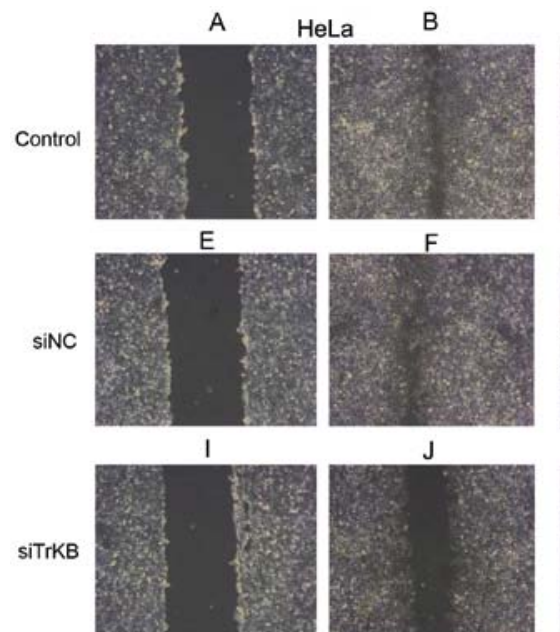

M
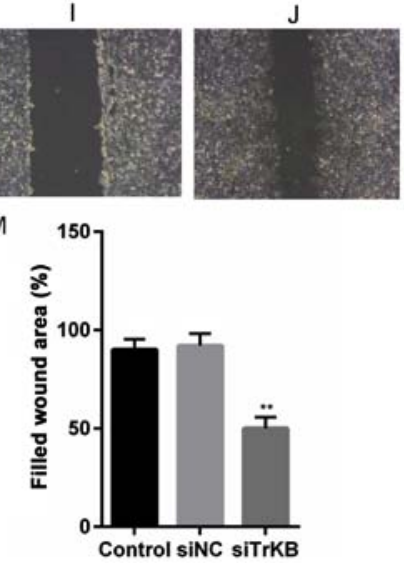
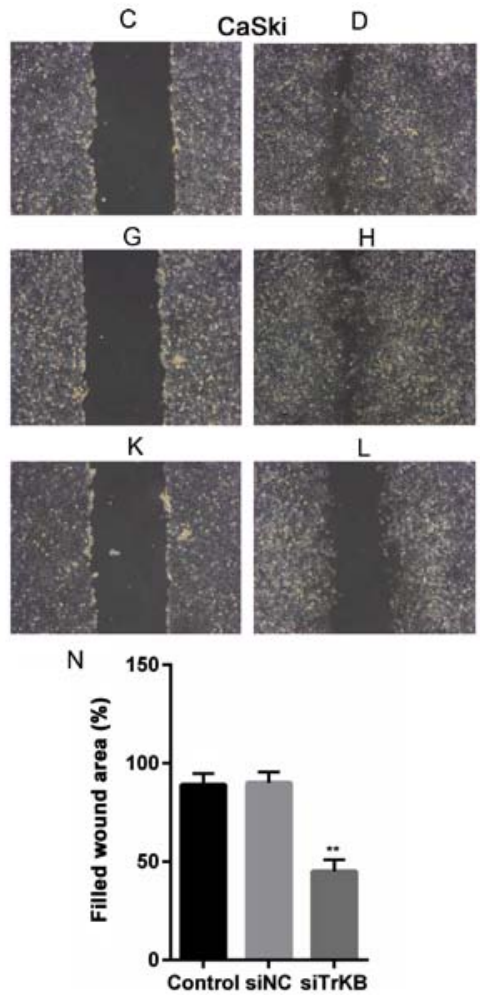

Figure 5. Silencing of TrKB markedly suppresses the proliferative and migratory abilities of the cells. The scratch wound healing assay revealed that the wound healing ability of the cells from the (A-D) control and (E-H) negative siRNA-transfected groups was significantly higher than that in cells transfected with TrKB siRNA (I-J). Approximately $90 \%$ of the wound healing rate was obtained in (M) HeLa and (N) CaSki cells, while it was only 50 and $35 \%$ of the wound healing rate in HeLa and CaSki cells transfected with siTrKB; ${ }^{* *} \mathrm{P}<0.01$ vs. control. 

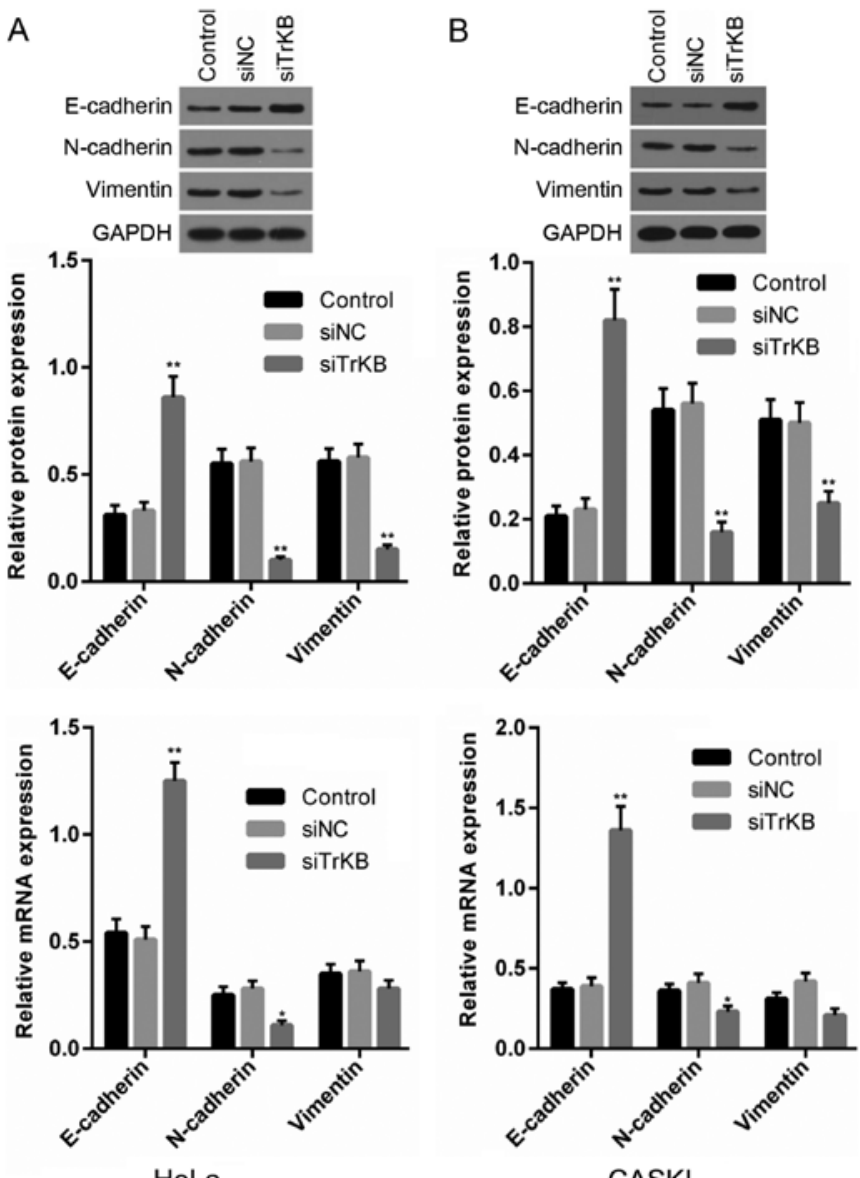

Figure 6. Downregulation of TrKB expression suppresses the expression of cell epithelial-mesenchymal transition (EMT) proteins. (A) In the HeLa cells, the expression levels of the EMT-associated proteins E-cadherin, and $\mathrm{N}$-cadherin or vimentin, at both the protein and mRNA level were upregulated and downregulated, respectively in the siTrKB group compared with the control and negative control groups. (B) Similar to the HeLa cells, in the CaSki cells, the expression levels of the EMT-associated proteins E-cadherin, and $\mathrm{N}$-cadherin or vimentin, were upregulated and downregulated, respectively in the siTrKB group compared with the control and negative control groups. ${ }^{*} \mathrm{P}<0.05$ vs. control; ${ }^{* *} \mathrm{P}<0.01$ vs. control.

EMT-related proteins, including E-cadherin, $\mathrm{N}$-cadherin and vimentin. It was clearly shown that in both the HeLa and CaSki cells, E-cadherin expression at both the protein and mRNA levels was upregulated in the TrKB siRNA-transfected group compared with that from the control and negative siRNAtransfected groups (Fig. 6). By contrast, $\mathrm{N}$-cadherin and vimentin expression levels were downregulated in the $\operatorname{TrKB}$ siRNA-transfected group compared with that from the control and negative siRNA-transfected groups in both the HeLa and CaSki cells. These results indicated that the silencing of $\operatorname{TrKB}$ inhibited the migration and invasion of the HeLa and CaSki cells.

Downregulation of TrKB affects the expression of proteins associated with invasion. Our above-mentioned experiments suggested that the cell migratory and invasive abilities were suppressed in both the HeLa and CaSki cells following the downregulation of TrKB. Hence, we determined the changes in the expression of proteins associated with invasion, such as MMP2, MMP9 and TMP2. As shown in Fig. 7, the protein
A
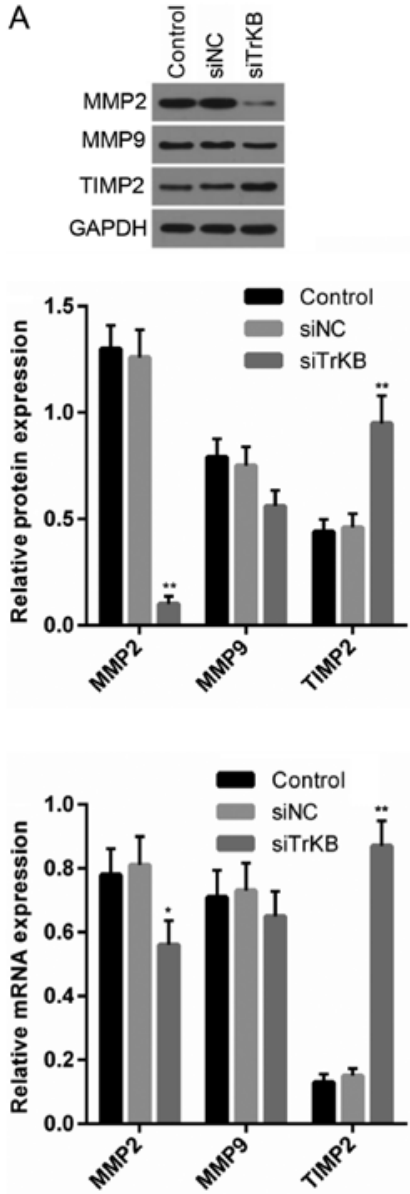

HeLa
B
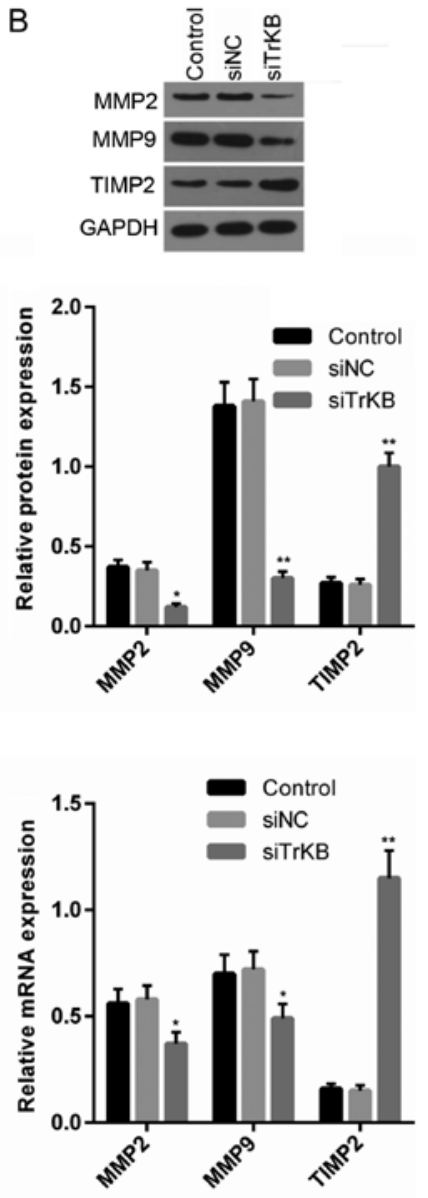

CASKI
Figure 7. Downregulation of TrKB suppresses the protein expression of MMP2 and TIMP2 in both HeLa and CaSki cells. (A) The mRNA and protein expression levels of MMP2 and TIMP2 in HeLa cells in which TrKB was knocked down were reduced and increased, respectively compared to the control and siNC groups. (B) The mRNA and protein expression levels of MMP2 or MMP9 and TIMP2 in CaSki cells transfected with siTrKB were reduced and increased, respectively compared to the control and siNC groups. ${ }^{*} \mathrm{P}<0.05$ vs. control; ${ }^{* *} \mathrm{P}<0.01$ vs. control.

expression of MMP2 was markedly abrogated in both the HeLa and CaSki cells transfected with TrKB siRNA compared with that in the control and negative siRNA-transfected groups, while MMP2 mRNA expression was slightly decreased in the cells transfected with TrKB siRNA compared with that in the control and negative siRNA-transfected groups. No significant changes were observed for MMP9 protein and mRNA expression in the HeLa cells between all groups, while the MMP9 protein level was markedly downregulated in the cells transfected with TrKB siRNA compared with the control and negative siRNA-transfected groups in the CaSki cells. However, the protein and mRNA expression levels of TMP2 were significantly elevated in both the HeLa and CaSki cells transfected with TrKB siRNA compared with that in the control and negative siRNA-transfected groups.

Silencing $\operatorname{Tr} K B$ expression attenuates the activation of the ERK and PI3K/AKT pathways. To explore the mechanisms responsible for the inhibitory effects of the silencing of the expression of TrKB on the cells, we examined the ERK, 
A
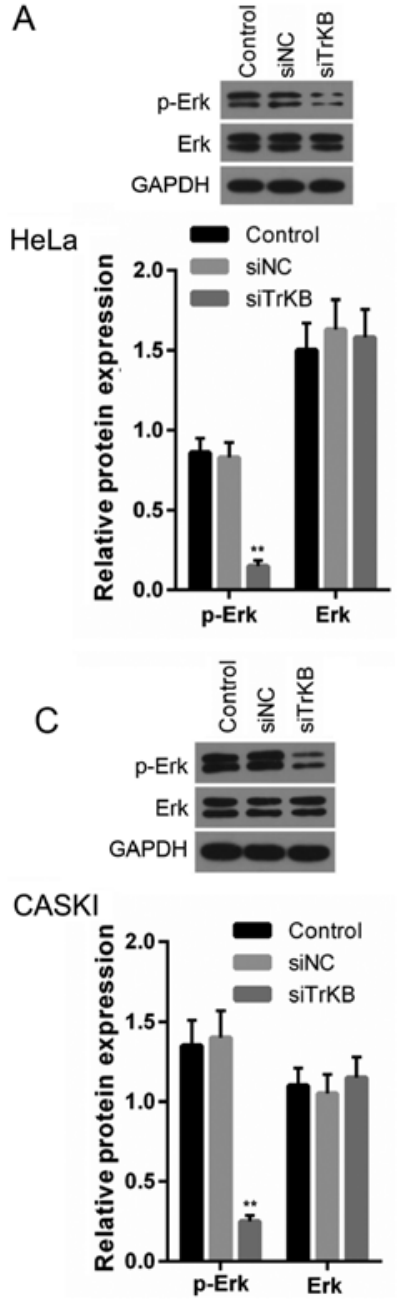
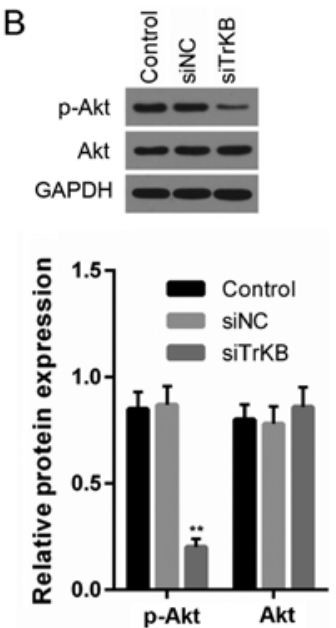

D
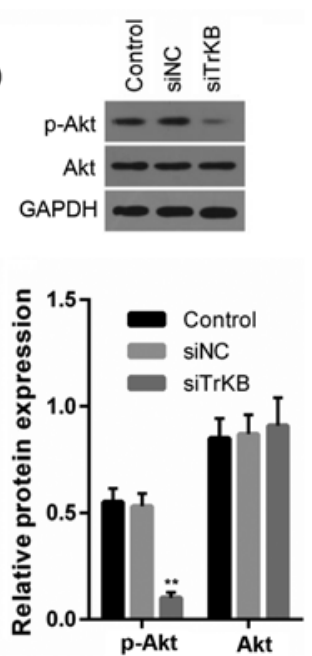

Figure 8. Knockdown of TrKB inhibits the activation of the ERK, PI3K/AKT pathways. Western blot analysis revealed that the levels of p-ERK, p-AKT in both the (A and B) HeLa and (C and D) CaSki cells were significantly decreased in cells in which TrKB was knocked down compared to those in cells from the control and negative TrKB siRNA groups. ${ }^{* * *} \mathrm{P}<0.01$ vs. control.

PI3K/AKT signaling pathways. As shown in Fig. 8, the levels of p-ERK, p-AKT in both the HeLa and CaSki cells were significantly decreased in the cells transfected with TrKB siRNA compared to those in the cells from the control and negative siRNA-transfected groups.

Downregulation of TrKB inhibits tumor growth. To determine whether the knockdown of TrKB expression affects the growth of tumors in nude mice, HeLa cells from the control and negative siRNA-transfected groups were injected into the nude mice and tumors were allowed to grow for 15 days. As shown in Fig. 9A and B, the tumors derived from negative siRNAtransfected cells were similar to those of the controls as regards size and weight, while tumors derived from siTrKB-transfected cells were smaller and weighed less. We further examined the expression levels of TrKB and BDNF in these tumors by immunohistochemical analysis. The results revealed that both TrKB and BDNF expression levels were downregulated in tumors derived from siTrKB-transfected cells compared to the levels in tumors developed by cells from the control and negative siRNA-transfected groups (Fig. 9C and D). Taken

together, these results indicate that TrKB is essential for tumor growth.

\section{Discussion}

Previous studies have shown that a high expression of $\mathrm{BDNF} / \mathrm{TrKB}$ is closely associated with EMT and is linked to tumor growth, invasion and metastasis $(18,29)$. To the best of our knowledge, the present study is the first to demonstrate a strong association of a high BDNF/TrKB expression with tumor size, grade of differentiation, positive lymph node metastasis and a poor survival of patients with cervical cancer. However, there was no significant association between TrKB and clinicopathological parameters. Furthermore, a high BDNF/TrKB expression enhanced cervical cancer cell growth, migration and invasion via the promotion of EMT and the upregulation of MMP2 and MMP9 expression. Our results suggest that BDNF/ TrKB may be considered as novel biomarkers in cervical cancer. In addition, our results are supported by those of previous studies in which the BDNF/TrKB signaling pathway was shown to be essential for EMT, and for the activation of the PI3K/AKT and Ras/MAPK cascades (30-32).

BDNF was initially known as a neurotrophic factor, which is essential for maintaining the survival of neurons, promoting their growth, differentiation and regeneration following injury in the peripheral and central nervous system $(7,33,34)$. BDNF expression has been found in many non-union systems, such as blood vessels (endothelial and smooth muscle cells), bone marrow and heart, and an increased microvascular density has been observed in tissues with an overexpression of BDNF (35-37). In addition, studies have found that BDNF and its receptors are closely associated with gastric cancer, lung cancer, hepatocellular carcinoma, ovarian cancer and prostate cancer and other solid tumors (9-12). Furthermore, BDNF is also known to be involved in the regulation of endothelial cells and is linked to angiogenesis $(38,39)$. However, few studies have investigated the role of BDNF in cervical cancer. In the present study, a high positive ( $60 \%$ ) expression of BDNF was observed in cervical cancer tissues. Our results also revealed that the protein and mRNA expression levels of BDNF were markedly higher in cervical cancer tissues than in normal tissues. Furthermore, a high expression of BDNF was also found in several cervical cancer cell lines.

TrkB is a highly glycosylated molecule consisting of 821 amino acid residues, and the extracellular domain consists of a signal peptide consisting of 32 amino residues (40). The BDNF-specific receptor is TrkB, and plays a biological effect mainly dependent on the binding of the receptor TrkB, promoting of TrkB homodimer formation, and activating of the receptor tyrosine kinase activity, which increases the phosphorylation of tyrosine residues (41). Moreover, activated TrkB can simulate the expression of a variety of proteins and enzymes, thereby promoting the transcription of immediate and delayed response genes or by being directly involved in a variety of physiological responses $(40,41)$. Additionally, BDNF/ TrkB is not only expressed in multiple myeloma and neuroblastoma (42), but also in non-neurogenic tumors, such as lung cancer, liver cancer, pancreatic cancer, nephroblastoma and even in virus-transformed B lymphocytes $(9-12,43,44)$. In particular, the positive expression of BDNF/TrkB may be closely related 


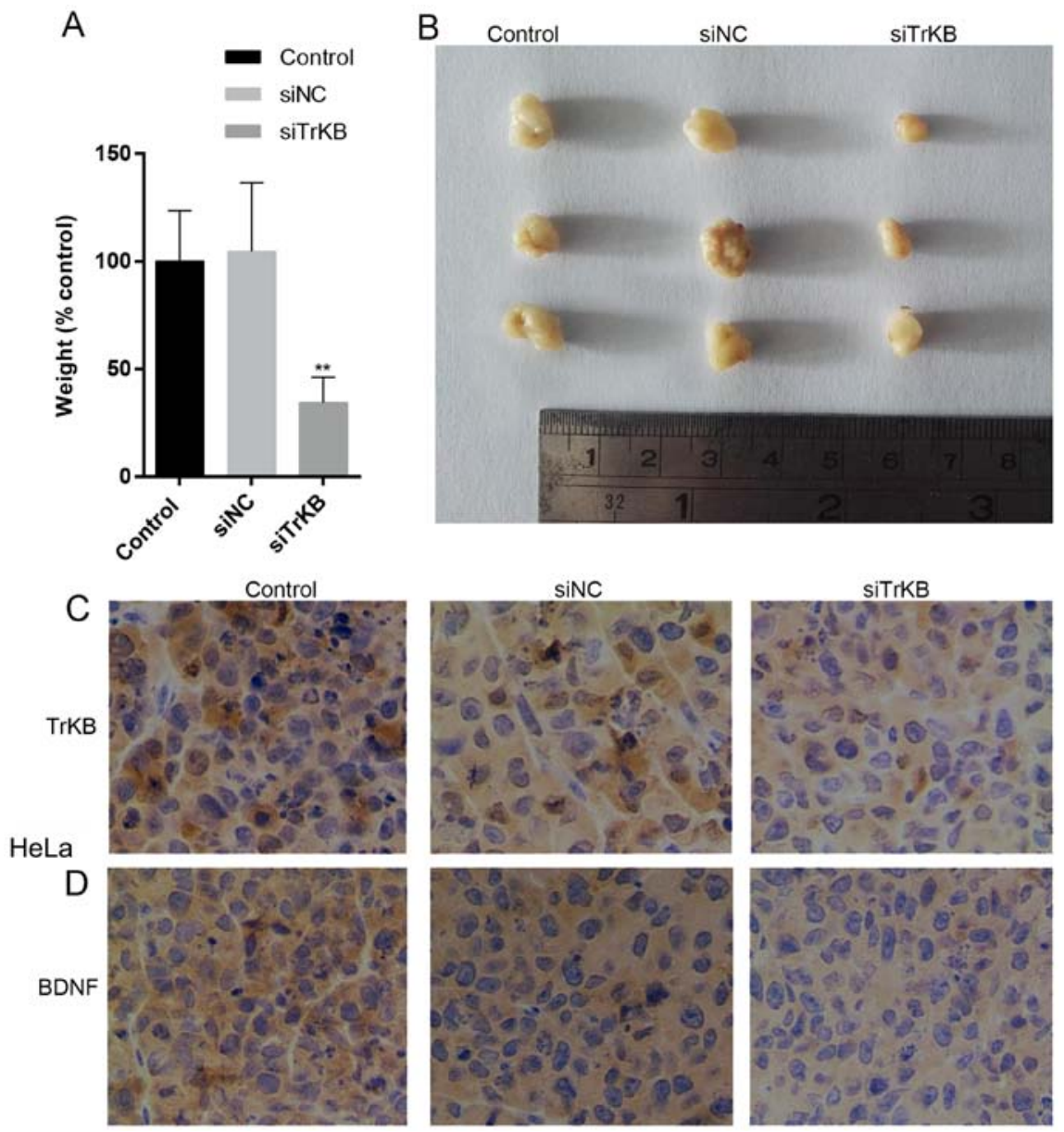

Figure 9. Silencing of TrKB suppresses tumor growth. The HeLa cells were injected into nude mice and tumors were allowed to grow for 15 days. The (A) tumor weight was lighter and (B) tumor size was smaller in cells with a downregulated TrKB expression compared to the control and siNC groups. Tumor weight is presentd as the fold change compared to the control. Immunohistochemical analysis revealed that the expression levels of (C) TrKB and (D) BDNF in tumors transfected with siTrKB were lower than those in the control and siNC groups. ${ }^{* *} \mathrm{P}<0.01$ vs. control.

to the development and progression of ovarian cancer, which may promote the development of ovarian epithelial carcinoma $(11,45)$. In the present study, a high positive expression of TrKB, as of BDNF, in cervical cancer tissues and cell lines was observed compared to the normal tissues and cells, respectively. Furthermore, patients with a positive expression of both BDNF and TrKB exhibited a poorer prognosis than those with either BDNF- or TrKB-positive expression alone and with a negative expression of both. These results can be partially confirmed by two previous studies $(26,27)$. It has been found that an autocrine loop exists between TrkB and BDNF in neuroblastoma and myeloma, in which a high expression of BDNF induces the increased expression of TrkB $(46,47)$. Notably, we found that the silencing of TrKB induced the downregulation of BDNF. Hence, we hypothesized that there other mechanisms involved and these warrant further investigation.

E-cadherin is linked to the morphogenesis of epithelial cells, and to the maintenance of the integrity of epithelial tissues $(48,49)$. A decreased E-cadherin expression is associated with the invasion and metastasis of tumors, including gastric, breast and pancreatic endocrine cancer (48-52). Recent experiments have indicated that the activation of BDNF/TrkB can lead to the occurrence of EMT (30). In addition, it has been reported that a high expression of BDNF/TrkB leads to EMT in head and neck squamous carcinoma cell lines (31), and is associated with EMT in colorectal cancer cells, leading to enhanced tumor metastasis (32). In agreement with these findings, our results suggested that the downregulated expression of E-cadherin was an important stimulus of EMT, which was mediated by the activation of the BDNF/TrkB pathway in cervical cancer cell lines. We found that a high expression of $\mathrm{N}$-cadherin and vimentin was closely associated with the activation of the BDNF/TrkB pathway. N-cadherin and vimentin have been implicated in the process EMT, resulting in phenotypic changes in many cancer cells $(53,54)$. In the present study, the silencing of TrKB induced a decrease in both $\mathrm{N}$-cadherin and vimentin, which supported the stimulatory effect of BDNF/TrkB on EMT observed in other studies $(30,31,53,54)$. We further examined the effects of the knockdown of TrKB by siRNA on the proliferation, migration and invasion of cervical cancer cell lines. Our results revealed that the proliferation, migration and invasion of the cervical cancer cell lines, HeLa and CaSki, were suppressed after the cells were transfected with TrKB siRNA. MMP2 and MMP9 are members of the MMP family and have been implicated in the invasion and metastasis of cancer cells (55). In this study, the decreased expression of MMP2 and MMP9 supported the suppressed proliferation, migration and invasion of the cervical cancer cell lines (MMP9 was not significantly 
affected in the HeLa cells and CaSki cells) transfected with TrKB siRNA. TIMP2, as previously demonstrated (56), was related to inhibition of cell migration and invasion, and its expression was increased in cells in which TrKB was knocked down. These results suggest that BDNF/TrkB exerts a potent simulatory effect on cell growth, migration and invasion via the regulation of E-cadherin, N-cadherin, vimentin, MMP2, MMP9 and TIMP2.

Recent studies have indicated that when TrkB binds to its ligand, BDNF, multiple signaling cascades can be stimulated, including the ERK and PI3K/AKT pathways (57-59). In addition, the TrkB/BDNF signaling pathway induces EMT and enhances cell invasion and metastasis by regulating downstream genes, such as E-cadherin, N-cadherin and vimentin $(18,19)$. Therefore, in this study we examined whether the TrkB/ BDNF signaling pathway is linked to the ERK and PI3K/AKT pathways, thereby inducing cell proliferation, migration and invasion. Our results revealed that high levels of phosphorylated ERK were observed in the HeLa and CaSki cells. We found that the phosphorylation of ERK was evidently decreased after the cells were transfected with TrKB siRNA. Moreover, the phosphorylation of PI3K/AKT was also observed to be markedly decreased after the silencing of TrKB in the HeLa and CaSki cells. Furthermore, the decrease in TrkB expression affected the expression of EMT-related transcription factors, such as E-cadherin, N-cadherin and vimentin. Additionally, the expression levels of genes associated with cell invasion, such as MMP2, MMP9 and TIMP2 were also affected by the silencing of $\operatorname{TrKB}$ in the cells. These results suggest that the downregulation of TrkB/BDNF signaling suppresses cell metastasis, proliferation and invasion by reducing downstream gene expression via the inhibition of the ERK and PI3K/AKT pathways.

In conclusion, we identified two new molecular biomarkers, TrkB/BDNF, present in cervical cancer that regulate cell proliferation, invasion and metastasis. Furthermore, we demonstrate that the TrkB/BDNF pathway may be a potential therapeutic candidate for the targeted therapy of cervical cancer.

\section{References}

1. Singhal P, Hussain S, Thakur N, Batra S, Salhan S, Bhambani S and Bharadwaj M: Association of MDM2 and p53 polymorphisms with the advancement of cervical carcinoma. DNA Cell Biol 32: 19-27, 2013.

2. Fukushima K, Ogawa S, Tsukimori K, Kobayashi H and Wake N: Can we diagnose invasive cervical cancer during pregnancy as precise as in nonpregnant women? Maternal and perinatal outcome in pregnancies complicated with cervical cancers. Int J Gynecol Cancer 19: 1439-1445, 2009.

3. Qu J, Lu W, Li B, Lu C and Wan X: WWOX induces apoptosis and inhibits proliferation in cervical cancer and cell lines. Int J Mol Med 31: 1139-1147, 2013.

4. Zhao Y, Shen L, Chen X, Qian Y, Zhou Q, Wang Y, Li K, Liu M, Zhang S and Huang X: High expression of PKM2 as a poor prognosis indicator is associated with radiation resistance in cervical cancer. Histol Histopathol 30: 1313-1320, 2015.

5. Okugawa Y, Tanaka K, Inoue Y, Kawamura M, Kawamoto A, Hiro J, Saigusa S, Toiyama Y, Ohi M, Uchida K, et al: Brainderived neurotrophic factor/tropomyosin-related kinase B pathway in gastric cancer. Br J Cancer 108: 121-130, 2013.

6. Tanaka K, Okugawa Y, Toiyama Y, Inoue Y, Saigusa S, Kawamura M, Araki T, Uchida K, Mohri Y and Kusunoki M: Brain-derived neurotrophic factor (BDNF)-induced tropomyosin-related kinase B (Trk B) signaling is a potential therapeutic target for peritoneal carcinomatosis arising from colorectal cancer. PLoS One 9: e96410, 2014.
7. Kelly-Spratt KS, Klesse LJ and Parada LF: BDNF activated TrkB/IRR receptor chimera promotes survival of sympathetic neurons through Ras and PI-3 kinase signaling. J Neurosci Res 69: 151-159, 2002.

8. Kimura A, Namekata K, Guo X, Harada C and Harada T: Neuroprotection, growth factors and BDNF-TrkB signalling in retinal degeneration. Int J Mol Sci 17: 1584, 2016.

9. Okamura K, Harada T, Wang S, Ijichi K, Furuyama K, Koga T, Okamoto T, Takayama K, Yano T and Nakanishi Y: Expression of TrkB and BDNF is associated with poor prognosis in non-small cell lung cancer. Lung Cancer 78: 100-106, 2012.

10. Choi B, Lee EJ, Shin MK, Park YS, Ryu MH, Kim SM, Kim EY, Lee HK and Chang EJ: Upregulation of brain-derived neurotrophic factor in advanced gastric cancer contributes to bone metastatic osteolysis by inducing long pentraxin 3 . Oncotarget 7: 55506-55517, 2016.

11. Au CW, Siu MK, Liao X, Wong ES, Ngan HY, Tam KF, Chan DC, Chan QK and Cheung AN: Tyrosine kinase B receptor and BDNF expression in ovarian cancers - Effect on cell migration, angiogenesis and clinical outcome. Cancer Lett 281: 151-161, 2009.

12. Bronzetti E, Artico M, Forte F, Pagliarella G, Felici LM, D'Ambrosio A, Vespasiani G and Bronzetti B: A possible role of BDNF in prostate cancer detection. Oncol Rep 19: 969-974, 2008.

13. Huang YT, Lai PC, Wu CC, Hsu SH, Cheng CC, Lan YF and Chiu TH: BDNF mediated TrkB activation is a survival signal for transitional cell carcinoma cells. Int J Oncol 36: 1469-1476, 2010.

14. Xiang J, Pan J, Chen F, Zheng L, Chen Y, Zhang S and Feng W: L-3-n-butylphthalide improves cognitive impairment of APP/ PS1 mice by BDNF/TrkB/PI3K/AKT pathway. Int J Clin Exp Med 7: 1706-1713, 2014.

15. Taube JH, Herschkowitz JI, Komurov K, Zhou AY, Gupta S, Yang J, Hartwell K, Onder TT, Gupta PB, Evans KW, et al: Core epithelial-to-mesenchymal transition interactome gene-expression signature is associated with claudin-low and metaplastic breast cancer subtypes. Proc Natl Acad Sci USA 107: 15449-15454, 2010.

16. Yang CC, Zhu LF, Xu XH, Ning TY, Ye JH and Liu LK: Membrane type 1 matrix metalloproteinase induces an epithelial to mesenchymal transition and cancer stem cell-like properties in SCC9 cells. BMC Cancer 13: 171, 2013.

17. Cufí S, Vazquez-Martin A, Oliveras-Ferraros C, MartinCastillo B, Joven J and Menendez JA: Metformin against TGF $\beta$-induced epithelial-to-mesenchymal transition (EMT): From cancer stem cells to aging-associated fibrosis. Cell Cycle 9: 4461-4468, 2010

18. Bao W, Qiu H, Yang T, Luo X, Zhang H and Wan X: Upregulation of TrkB promotes epithelial-mesenchymal transition and anoikis resistance in endometrial carcinoma. PLoS One 8: e70616, 2013.

19. Ricci A, De Vitis C, Noto A, Fattore L, Mariotta S, Cherubini E, Roscilli G, Liguori G, Scognamiglio G, Rocco G, et al: TrkB is responsible for EMT transition in malignant pleural effusions derived cultures from adenocarcinoma of the lung. Cell Cycle 12: 1696-1703, 2013

20. Zhang J, Zhang Y, Liu S, Zhang Q, Wang Y, Tong L, Chen X, Ji Y, Shang Q, Xu B, et al: Metadherin confers chemoresistance of cervical cancer cells by inducing autophagy and activating ERK/NF- $\kappa$ B pathway. Tumour Biol 34: 2433-2440, 2013.

21. Ming P, Cai T, Li J, Ning Y, Xie S, Tao T and Tang F: A novel arylbenzofuran induces cervical cancer cell apoptosis and G1/S arrest through ERK-mediated Cdk2/cyclin-A signaling pathway. Oncotarget 7: 41843-41856, 2016.

22. Sun Q, Liang Y, Zhang T, Wang K and Yang X: ER- $\alpha 36$ mediates estrogen-stimulated MAPK/ERK activation and regulates migration, invasion, proliferation in cervical cancer cells. Biochem Biophys Res Commun 487: 625-632, 2017.

23. Im SR and Jang YJ: Aspirin enhances TRAIL-induced apoptosis via regulation of ERK1/2 activation in human cervical cancer cells. Biochem Biophys Res Commun 424: 65-70, 2012.

24. Li X, Yang Z, Song W, Zhou L, Li Q, Tao K, Zhou J, Wang X, Zheng Z, You N, et al: Overexpression of Bmi-1 contributes to the invasion and metastasis of hepatocellular carcinoma by increasing the expression of matrix metalloproteinase (MMP)-2, MMP-9 and vascular endothelial growth factor via the PTEN/ PI3K/Akt pathway. Int J Oncol 43: 793-802, 2013.

25. Li B, Tsao SW, Li YY, Wang X, Ling MT, Wong YC, He QY and Cheung ALM: Id-1 promotes tumorigenicity and metastasis of human esophageal cancer cells through activation of PI3K/AKT signaling pathway. Int J Cancer 125: 2576-2585, 2009. 
26. Cornelio DB, DE Farias CB, Prusch DS, Heinen TE, Dos Santos RP, Abujamra AL, Schwartsmann G and Roesler R: Influence of GRPR and BDNF/TrkB signaling on the viability of breast and gynecologic cancer cells. Mol Clin Oncol 1: 148-152, 2013.

27. Moon A, Won KY, Lee JY, Kang I, Lee SK and Lee J: Expression of BDNF, TrkB, and p53 in early-stage squamous cell carcinoma of the uterine cervix. Pathology 43: 453-458, 2011.

28. Benedet JL, Bender H, Jones H III, Ngan HY and Pecorelli S; FIGO Committee on Gynecologic Oncology: FIGO staging classifications and clinical practice guidelines in the management of gynecologic cancers. Int J Gynaecol Obstet 70 209-262, 2000.

29. Alonso-Alconada L, Eritja N, Muinelo-Romay L, Barbazan J, Lopez-Lopez R, Matias-Guiu X, Gil-Moreno A, Dolcet X and Abal M: ETV5 transcription program links BDNF and promotion of EMT at invasive front of endometrial carcinomas. Carcinogenesis 35: 2679-2686, 2014.

30. Jia S, Wang W, Hu Z, Shan C, Wang L, Wu B, Yang Z, Yang X and Lei D: BDNF mediated TrkB activation contributes to the EMT progression and the poor prognosis in human salivary adenoid cystic carcinoma. Oral Oncol 51: 64-70, 2015.

31. Lee J, Jiffar T and Kupferman ME: A novel role for BDNF-TrkB in the regulation of chemotherapy resistance in head and neck squamous cell carcinoma. PLoS One 7: e30246, 2012.

32. Fujikawa H, Tanaka K, Toiyama Y, Saigusa S, Inoue Y, Uchida K and Kusunoki M: High TrkB expression levels are associated with poor prognosis and EMT induction in colorectal cancer cells. J Gastroenterol 47: 775-784, 2012.

33. Wong J: Neurotrophin Signaling and Alzheimer's Disease Neurodegeneration - Focus on BDNF/TrkB Signaling, Trends in Cell Signaling Pathways in Neuronal Fate Decision, Dr Sabine Wislet-Gendebien (ed). InTech, 2013. DOI: 10.5772/53364. Available from: https://www.intechopen.com/books/trends-in cell-signaling-pathways-in-neuronal-fate-decision/neurotrophin -signaling-and-alzheimer-s-disease-neurodegeneration-focus-on -bdnf-trkb-signaling.

34. Eberhardt KA, Irintchev A, Al-Majed AA, Simova O, Brushart TM, Gordon T and Schachner M: BDNF/TrkB signaling regulates HNK-1 carbohydrate expression in regenerating motor nerves and promotes functional recovery after peripheral nerve repair. Exp Neurol 198: 500-510, 2006.

35. Berner A, Reichert JC, Müller MB, Zellner J, Pfeifer C, Dienstknecht T, Nerlich M, Sommerville S, Dickinson IC, Schütz MA, et al: Treatment of long bone defects and non-unions: From research to clinical practice. Cell Tissue Res 347: 501-519, 2012.

36. Chen J, Li Y and Chopp M: Intracerebral transplantation of bone marrow with BDNF after MCAo in rat. Neuropharmacology 39: 711-716, 2000

37. Fulgenzi G, Tomassoni-Ardori F, Babini L, Becker J, Barrick C, Puverel S and Tessarollo L: BDNF modulates heart contraction force and long-term homeostasis through truncated TrkB.T1 receptor activation. J Cell Biol 210: 1003-1012, 2015.

38. Pouneh Kermani BH: BDNF: A newly described mediator of angiogenesis. Trends Cardiovasc Med 17: 140, 2007.

39. Hong JH, Park HM, Byun KH, Lee BH, Kang WC and Jeong GB: BDNF expression of macrophages and angiogenesis after myocardial infarction. Int J Cardiol 176: 1405-1408, 2014.

40. Jerónimo-Santos A, Vaz SH, Parreira S, Rapaz-Lérias S, Caetano AP, Buée-Scherrer V, Castrén E, Valente CA, Blum D, Sebastião AM, et al: Dysregulation of TrkB receptors and BDNF function by amyloid- $\beta$ peptide is mediated by calpain. Cereb Cortex 25: 3107-3121, 2015 .

41. Feng N,Huke S, Zhu G, Tocchetti CG, Shi S, Aiba T, Kaludercic N, Hoover DB, Beck SE, Mankowski JL, et al: Constitutive BDNF/ TrkB signaling is required for normal cardiac contraction and relaxation. Proc Natl Acad Sci USA 112: 1880-1885, 2015.

42. Brodeur GM, Nakagawara A, Yamashiro DJ, Ikegaki N, Liu XG, Azar CG, Lee CP and Evans AE: Expression of TrkA, TrkB and TrkC in human neuroblastomas. J Neurooncol 31: 49-55, 1997.
43. Eggert A, Grotzer MA, Zhao H, Brodeur GM and Evans AE: Expression of the neurotrophin-receptor TrkB predicts outcome in nephroblastomas: Results of a pilot-study. Klin Padiatr 213: 191-196, 2001 (In German).

44. Wang HY, Crupi D, Liu J, Stucky A, Cruciata G, Di Rocco A, Friedman E, Quartarone A and Ghilardi MF: Repetitive transcranial magnetic stimulation enhances BDNF-TrkB signaling in both brain and lymphocyte. J Neurosci 31: 11044-11054, 2011.

45. Siu MK, Wong OG and Cheung AN: TrkB as a therapeutic target for ovarian cancer. Expert Opin Ther Targets 13: 1169-1178, 2009.

46. Yang ZF, Ho DW, Lau CK, Tam KH, Lam CT, Poon RTP and Fan ST: Platelet activation during tumor development, the potential role of BDNF-TrkB autocrine loop. Biochem Biophys Res Commun 346: 981-985, 2006.

47. Polakowski N, Terol M, Nash I, Hoang K, Gazon H, Wurm T, Césaire R, Péloponèse JM, Mesnard JM and Lemasson I: A BDNF/TrKB autocrine loop stimulated by HBZ is involved in HTLV-1-infected cell-survival. Retrovirology 11 (Suppl 1): O57, 2014.

48. Bondow BJ, Faber ML, Wojta KJ, Walker EM and Battle MA: E-cadherin is required for intestinal morphogenesis in the mouse. Dev Biol 371: 1-12, 2012.

49. Fournier MV, Fata JE, Martin KJ, Yaswen P and Bissell MJ: Interaction of E-cadherin and PTEN regulates morphogenesis and growth arrest in human mammary epithelial cells. Cancer Res 69: 4545-4552, 2009.

50. Tamura G, Yin J, Wang S, Fleisher AS, Zou T, Abraham JM, Kong D, Smolinski KN, Wilson KT, James SP, et al: E-Cadherin gene promoter hypermethylation in primary human gastric carcinomas. J Natl Cancer Inst 92: 569-573, 2000.

51. Eger A, Aigner K, Sonderegger S, Dampier B, Oehler S, Schreiber M, Berx G, Cano A, Beug H and Foisner R: DeltaEF1 is a transcriptional repressor of E-cadherin and regulates epithelial plasticity in breast cancer cells. Oncogene 24: 2375-2385, 2005.

52. Chetty R1, Serra S and Asa SL: Loss of membrane localization and aberrant nuclear E-cadherin expression correlates with invasion in pancreatic endocrine tumors. Am J Surg Pathol 32: 413-419, 2008

53. Zhang X, Liu G, Kang Y, Dong Z, Qian Q and Ma X: N-cadherin expression is associated with acquisition of EMT phenotype and with enhanced invasion in erlotinib-resistant lung cancer cell lines. PLoS One 8: e57692, 2013.

54. Nakajima S, Doi R, Toyoda E, Tsuji S, Wada M, Koizumi M, Tulachan SS, Ito D, Kami K, Mori T, et al: N-cadherin expression and epithelial-mesenchymal transition in pancreatic carcinoma. Clin Cancer Res 10: 4125-4133, 2004

55. Kumar B, Koul S, Petersen J, Khandrika L, Hwa JS, Meacham RB, Wilson S and Koul HK: p38 mitogen-activated protein kinasedriven MAPKAPK2 regulates invasion of bladder cancer by modulation of MMP-2 and MMP-9 activity. Cancer Res 70: 832-841, 2010.

56. Lu KV, Jong KA, Rajasekaran AK, Cloughesy TF and Mischel PS: Upregulation of tissue inhibitor of metalloproteinases (TIMP)-2 promotes matrix metalloproteinase (MMP)-2 activation and cell invasion in a human glioblastoma cell line. Lab Invest 84: 8-20, 2004.

57. Kumamaru E, Numakawa $\mathrm{T}$, Adachi $\mathrm{N}$ and Kunugi $\mathrm{H}$ : Glucocorticoid suppresses BDNF-stimulated MAPK/ERK pathway via inhibiting interaction of Shp2 with TrkB. FEBS Lett 585: 3224-3228, 2011.

58. Revest JM, Le Roux A, Roullot-Lacarrière V, Kaouane N, Vallée M, Kasanetz F, Rougé-Pont F, Tronche F, Desmedt A and Piazza PV: BDNF-TrkB signaling through Erk1/2 MAPK phosphorylation mediates the enhancement of fear memory induced by glucocorticoids. Mol Psychiatry 19: 1001-1009, 2014.

59. Yao RQ, Qi DS, Yu HL, Liu J, Yang LH and Wu XX: Quercetin attenuates cell apoptosis in focal cerebral ischemia rat brain via activation of BDNF-TrkB-PI3K/Akt signaling pathway. Neurochem Res 37: 2777-2786, 2012. 